\title{
Assessing the extent of transport social exclusion among the elderly
}

\author{
Helena Titheridge, Kamalasudhan Achuthan, and Roger Mackett \\ Centre for Transport Studies, University College London ${ }^{a}$ \\ Juliet Solomon \\ TRaC, London Metropolitan University
}

\begin{abstract}
Social exclusion" is a concept that has become increasingly prominent in the UK and elsewhere in the last ten years. Social exclusion occurs as a result of a series of problems that prevent people from being able to participate in activities that are considered normal in their society. Some of these problems are related to issues of accessibility. This paper outlines work carried out in the context of the AUNT-SUE (Accessibility and User Needs in Transport in Sustainable Urban Environments) project to develop and model an appropriate set of accessibility benchmarks for older people. Results confirmed that the travel patterns of older people are very different from those of the average person in the UK and that it was necessary to tailor accessibility benchmarks to the characteristics of this group. A set of benchmarks was developed based on ability to undertake different types of activity. These benchmarks are currently being incorporated into AMELIA, a GIS-based tool for assessing the effect of different policy actions on accessibility. Issues that have arisen include how to model the myriad micro-level circumstances that affect the mobility of older people. Some initial analysis has shown that these details can make a substantial difference to the assessment of the accessibility of a destination. Examples are drawn from St Albans in Hertfordshire, UK.
\end{abstract}

Keywords: Accessibility, Elderly, Social exclusion, Benchmarks, Indicators

\section{Introduction}

"Social exclusion," as defined by the UK government (Cabinet Office 2007), is about more than income poverty; it is what happens "when people or places suffer from a series of problems such as unemployment, discrimination, poor skills, low incomes, etc." as a result of which they are unable to participate in activities that would reasonably be considered normal in their society (Burchardt et al. 2002; Oppenheim 1998).

Transport can contribute to social exclusion by limiting access to jobs, education and training, health services, sports and recreation facilities, and social networks whether due to the cost of transport or the availability of appropriate transport. Limited access to transport can make it difficult for those on low incomes, the elderly and those with disabilities to balance subsistence and maintenance activities with family life, as a result the number and range of activities they can undertake becomes restricted and localized (EC, 2004; SEU, 2003).

${ }^{a}$ Corresponding author Helena Titheridge: h.titheridge@ucl.ac.uk 
This paper describes results of work carried out as part of the AUNT-SUE (Accessibility and User Needs in Transport for Sustainable Urban Environments) project. The research aims to establish a set of benchmarks of accessibility, based on what certain groups believe are necessary for feeling included in their desired social context. The research also aims to develop a tool (AMELIA - A Methodology for Enhancing Life by Increasing Accessibility) that can be used by local authorities and others to assess the likely impact of different policies and actions on the accessibility of different groups of people in terms of these benchmarks. This tool is described later in the paper and was applied to the case of older people in the town of St Albans, Hertfordshire, UK.

\section{Accessibility Benchmarking}

There are many different measures of accessibility that vary in terms of detail, parameters and perspectives. (These measures have been reviewed elsewhere, e.g. Geurs and Eck (2001); Geurs and Wee (2004); Halden et al. (2005)). Practitioners working in different fields currently use a disparate range of indicators, benchmarks and standards to assess the accessibility of activity destinations for the "average person," and to identify geographical areas that are deemed to be relatively inaccessible, e.g. distance of residence from a bus stop, or time taken on a particular journey or journey stage. These types of measures are often assessed using network analysis within geographical information systems (GIS) (Jones and Wixey 2005).

The UK Department for Transport (DfT), for example, has developed a set of national accessibility indicators based on the percentage of the population (or an appropriate sub-group) who can reach key destinations within specified time thresholds (DfT, 2005a). These indicators say nothing, however, about what individual users can actually access given their unique sets of constraints, nor about what they might actually need (Handy and Niemeier 1997; Oppenheim 1998). Furthermore, relatively little is known about what people in particular circumstances regard as an acceptable amount of travel to reach friends, shops, places of work, and so on. Miller (2005) stresses the need to use individual rather than place-based accessibility measures. The Matisse Consortium 2003b suggests that accessibility needs to be seen in a broader context, with locations or activities only deemed accessible if the individual perceives the journey to be possible, and also that assessments of accessibility to services should take into account the perceptions, aspirations and expectations of the community 2003a.

Clearly, any benchmarks or indicators used must be concerned with "reasonable" access, both from the point of view of transport users and from the point of view of the law, if they are to have any validity. Furthermore, they should acknowledge both physical and mental disability. "Reasonable" is a description which, for the purposes of the present study, is translated for the transport users as "acceptable." It is, however, perhaps more commonly used in a legal context (Male and Spiteri 2005).

Equity is another important consideration (Solomon and Titheridge 2007). Equity matters because inequities violate the sense of fairness of many individuals; experimental evidence suggests that many people behave in ways consistent with a concern for fairness, in addition to caring about how they fare individually (World Bank 2006). Equity, as presented in the World Development Report (World Bank 2006), is based on two principles: equality of opportunity and avoidance of absolute deprivation (minimum threshold of need) — "[i] ndividuals should have equal opportunities to pursue a life of their choosing and be spared from extreme depri- 
vation in outcomes" (World Bank 2006, p.2). It should be noted here that however equal the opportunities given to people, one would "always expect to observe some differences in outcomes owing to differences in preferences, talents, effort, and luck" (World Bank 2006). As noted previously, a lack of transport access often results in a significant curtailment of social and economic opportunities, and therefore can contribute to an inequitable society. The aim of this research is not equal provision for all, which would be impossible and might be unfair; rather, it is equitable (fair or just) provision, meeting needs and desires-which would, following a principle elucidated by Rawls (1971, p.86) attempt to provide some redress for undeserved inequality.

In terms of accessibility limitations, aging and physical disability can be treated together for certain purposes. There are two ways of viewing disability or the limitations of old age: one is through the individual or medical model, which assumes that the individual is in some way outside the norm; the other is through the social model, which "treats disability as a socially determined disadvantage that accrues to those with an impairment" (Male and Spiteri 2005).

One of the difficulties in defining a set of accessibility benchmarks for assessing social inclusion is that it is not possible to say in any absolute sense that a person is or is not socially excluded or that this is or is not related to access and mobility. Within current knowledge and conceptual frameworks it is difficult to describe or analyze the extent to which a person is unable to participate in activities that would be considered "normal" in his or her society, partly because there is a strong element of relativity involved in what constitutes "normal" (or "reasonable") in the context of transport social exclusion. Even for a single individual there may be several sets of societal norms involved, from familial through local to national and global. There will, furthermore, be a whole collection of activities in which a person is able to participate, as well as many in which they cannot, both for transport-related and non-transport-related reasons (Burchardt et al. 2002).

One person's "norm" may include twice-weekly trips to a bar, one weekly shopping expedition, and a couple of visits to local friends, with perhaps very occasional trips further afield. The transport element of this lifestyle may be, for example, predominantly confined to walking. However, another person might assume that a daily commute journey by train or car, a couple of annual foreign holidays, a few weekends in the country, and a twice-monthly trip to an outof-town shopping center are "normal." Equally, some people would regard a "day" as finishing well before half past ten at night.

If transport policies and practices are to be "inclusive" in terms of the accessibility they permit, and if there is to be any rational basis for the evaluation of their inclusiveness, it is necessary to make approximate assessments of reasonable accessibility and mobility levels at which people feel (or are) "included" (Department of the Environment, Transport and the Regions/TRaC 2000). Benchmarks based on "reasonable" levels of accessibility must be set, and tools provided that will allow planners and other practitioners to assess the likely impact of different policies and actions on the number of people whose accessibility levels reach these benchmarks. However, whether or not an individual can reach a destination with reasonable ease is dependent on a range of micro-level features of the built environment and transport systems, as well as on the individual's capabilities, so any methodology developed needs to be able to deal with these types of micro-level detail but at the macro-scale required by transport planners. 


\section{Methodology}

Older people were defined as those aged 60 and over. This is an age at which many (particularly women and some public sector workers) within the UK retire. Over forty percent of those aged 60-64 in England are retired (National Statistics 2004). Retirement can result in substantial changes in lifestyle and thus travel behavior, and for many is accompanied by a substantial drop in income.

\subsection{Benchmark development}

Current journey patterns of older people were analyzed using data from the Great Britain (GB) National Travel Survey (NTS) aggregated for the years 1998 to 2001 (Department of the Environment, Transport and the Regions 2003a,b). NTS is a continuous household survey covering mainland Britain. Data are collected on the journeys made by each member of the household for each consecutive day of a seven-day period; additional data are collected on household and individual characteristics. The sample is stratified by region, car ownership, and other characteristics and is collected using "cluster sampling," in which spatially defined clusters within each stratum are sampled (Hayllar et al. 2005). Prior to 2002, approximately 5,000 individuals were sampled annually, thus the 1998-2002 data contains data on the travel of approximately 20,000 people, of which 4,529 were aged 60 and over.

These data were used to establish a "normal" range of journey attributes: frequency, purpose, time, mode, etc. (see Solomon and Titheridge 2006, for more details). These were compared with the Department for Transport indicators to see how far those currently proposed could be used in the assessment of accessibility improvements for older people.

Having established the strengths and weaknesses of the Department for Transport indicators, as applied to older people, the next task of the AUNT-SUE research project was to develop a set of benchmarks appropriate for older people. A pilot focus group of users of door-to-door transport was held (in Rotherham, West Yorkshire) to begin to establish expectations of a normal range of inclusive journeys for this group. Based on the results of this focus group, and on some embryonic consultation that was undertaken by those devising the Rotherham Community Transport Physical Disability and Sensory Impairment Strategy, some preliminary benchmarks were developed, framed in terms of the minimum acceptable number of different types of journeys. These benchmarks were then tested through a series of focus groups held in London and Hertfordshire.

\subsection{Development of AMELIA}

AMELIA (A Methodology for Enhancing Life by Increasing Accessibility) is a software tool that will enable planners to test the effectiveness of their transport policies at increasing social inclusion. AMELIA is partially based on existing accessibility models, and includes availability of travel modes (car, bicycle, walking, and public transport), trip purpose, socio-economic differentiation, travel time and travel cost. The user interface is through a GIS (Geographic Information System). The tool is intended to be used to establish how many people meet the accessibility benchmarks being developed within this project, with and without policy interventions. 
If the benchmarks and AMELIA are to be useful for comparing the likely effectiveness of different policies and interventions, it is necessary to establish how the benchmarks could be modeled within a GIS-based tool such as AMELIA. As this study is concerned with transport issues, it was assumed that once an individual reaches the location where a particular activity takes place (i.e. passes through the door of the building at an appropriate time) they will be able to complete that activity. The approach adopted, based on models of accessibility and GIS, means that the aspects of social exclusion that are represented are mainly physical; for example, barriers to movement on the pavement, changes of level, inaccessible vehicles, and high public transport fares. Even within the transport sphere, many aspects are difficult to address using conventional transport models; for example, information provision. This means that the types of barrier to access that can be investigated with AMELIA are mainly physical ones, and so the types of social exclusion that can be addressed are ones related to physical access (such as being in a wheelchair) or related to travel cost and time (such as being dependent on public transport to reach employment). These important issues can be examined using a GIS approach-as shown, for example, in research into wheelchair access using GIS (Beale et al. 2003; Matthews et al. 2003) and in the work by Jones et al. (2006) and Reneland (2005) on measuring pedestrian access.

\section{Walk journeys}

Concentrating initially on journeys that involve only walking, a set of criteria had to be established to specify which features of the built environment constitute a barrier to movement.

The inclusive mobility guidelines issued by the UK Department for Transport (Department for Transport 2005) were used as a starting point. These provide guidance on the design of footways, ${ }^{1}$ footpaths, and pedestrian areas; car parking, bus stops, taxi stands, and access to and within transport-related buildings; as well as signage, information and lighting, amongst others. This was supplemented with data from other similar sources such as EC (2004), ECMT (2006) and the Americans with Disabilities Act and the Architectural Barriers Act Accessibility Guidelines (United States Access Board 2004). Table 1 summarizes some of the parameters included within the DfT guidelines. Unfortunately not all aspects of the built environment are covered within this or the other above-mentioned documents.

Detailed data at the micro-level relating to the pedestrian environment were collected for the center of St Albans and for its district centers on the following: buildings, characteristics of the footway, road crossings, bus stops, car parking, and features. ${ }^{2}$ Macro level data based upon the local authority's information systems, including public transport routes and timetables and location of key services, and other sources such as the 2001 Census of Population, were assembled for the whole county of Hertfordshire.

\section{Public Transport Journeys}

Having established a method for modeling walking journeys, including bus stop access and egress, it was then possible to consider the public transport element of a journey, in particular bus stages. Decisions on the treatment of, for example, transfers between buses, maximum

\footnotetext{
${ }^{1}$ Footways are paths for pedestrians only.

${ }^{2}$ See Mackett et al. (2007) for more details on the collection techniques.
} 
Table 1: Physical parameters of people with different mobility characteristics.

\begin{tabular}{|c|c|c|}
\hline & Minimum horizontal gap* & $\begin{array}{l}\text { Maximum walking } \\
\text { distance without a } \\
\text { rest }\end{array}$ \\
\hline Reasonably fit adult & $700 \mathrm{~mm}$ & Not defined \\
\hline Adult with child & $1100 \mathrm{~mm}$ & Not defined \\
\hline $\begin{array}{l}\text { Person with limited } \\
\text { mobility, who uses no } \\
\text { walking aid }\end{array}$ & $700 \mathrm{~mm}$ & $100 \mathrm{~m}$ \\
\hline $\begin{array}{l}\text { Person who uses a walking } \\
\text { aid }\end{array}$ & $\begin{array}{l}\text { Walking stick: } 750 \mathrm{~mm} \text {. } \\
\text { Two walking sticks, crutches or a } \\
\text { walking frame: } 900 \mathrm{~mm}\end{array}$ & $50 \mathrm{~m}$ \\
\hline $\begin{array}{l}\text { Person who uses a } \\
\text { wheelchair }\end{array}$ & $\begin{array}{l}\text { Unaccompanied: } 900 \mathrm{~mm} \text {. } \\
\text { With ambulant person by side: } \\
1500 \mathrm{~mm}\end{array}$ & $150 \mathrm{~m}$ \\
\hline $\begin{array}{l}\text { Person with a visual } \\
\text { handicap }\end{array}$ & $\begin{array}{l}\text { Person using a long cane or } \\
\text { assistance dog: } 1100 \mathrm{~mm} \text {. } \\
\text { Person being guided: } 1200 \mathrm{~mm}\end{array}$ & $150 \mathrm{~m}$ \\
\hline
\end{tabular}

journey times, and journey costs as would affect older people were based on outcomes of the focus groups and the analysis of the NTS data.

\section{Results}

\subsection{Travel patterns of older people}

The NTS analysis showed that older people make very few work or education trips -58 trips per person per annum, less than seven percent of their total annual trips. Less than one percent of annual trips are for education. Those over 60 years of age make 33 percent more trips than the average person in a year for shopping and personal business purposes (Table 2). These types of trips make up nearly half of all journeys undertaken by those aged between 60 and 74, and nearly 60 percent of trips made by those over 75 years of age. In particular, elderly people tend to make substantially more trips for food shopping than average (173 compared with 119) and almost twice the number of trips for medical purposes, although medical trips still make up less than four percent of all trips. Elderly people tend to make slightly fewer social and leisure trips than average, but these trips account for 40 percent of the trips made by elderly people (30\% of all trips in Great Britain are for these purposes). Older people make more trips for the purpose of "just walking" than any other age group-eight percent of all trips compared with a UK average of just four percent.

Further analysis of the NTS data revealed differences between the travel patterns of elderly persons with differing levels of car availability (Table 3), and between those who experience 
Table 2: Trips per person per year by purpose for selected age groups.

\begin{tabular}{|c|c|c|c|c|}
\hline Journey Purpose & $\begin{array}{l}\text { Aged } \\
60-74\end{array}$ & Aged 75+ & Aged 60+ & GB mean \\
\hline Work \& Education & 83 & 6 & 58 & 275 \\
\hline Shopping \& Personal Business & 444 & 345 & 413 & 309 \\
\hline Leisure \& Social & 352 & 217 & 309 & 313 \\
\hline Escort & 65 & 21 & 51 & 129 \\
\hline Other & 2 & 1 & 2 & 2 \\
\hline Total & 947 & 591 & 832 & 1029 \\
\hline
\end{tabular}

Source: Department of the Environment, Transport and the Regions (2003a,b).

difficulties traveling either on foot or by bus and those who experience no difficulties (Table 4). For example, those who are the main driver of the household car make 50 percent more trips than those who occasionally have access to a car, and 80 percent more trips than those who do not have access to a car. Those with no access to a car do, however, make more food shopping trips than those with some access to a car, probably due to the difficulties in managing heavy loads when carrying shopping on foot or by public transport. Those elderly persons who experience travel difficulties tend to make fewer trips than those who experience no difficulties traveling, and the difference between these two groups widens with age. Those with travel difficulties make more medical trips.

Table 3: Trips per person per year by purpose and car availability

\begin{tabular}{lcccc}
\hline \multirow{2}{*}{ Journey purpose } & \multicolumn{3}{c}{ Aged 60+ } & \multirow{2}{*}{ All ages mean } \\
\cline { 2 - 4 } & Main Driver & H/hold Car & No Car & \\
\hline Work \& Education & 104 & 43 & 16 & 275 \\
Shopping \& Personal & 473 & 373 & 357 & 309 \\
Business & 414 & 281 & 213 & 313 \\
Leisure \& Social & 98 & 35 & 11 & 129 \\
Escort & 3 & 1 & 1 & 2 \\
Other & 1091 & 733 & 597 & 1029 \\
\hline Total & & & & \\
\hline Source: Depannnnnn
\end{tabular}

Source: Department of the Environment, Transport and the Regions (2003a,b).

Interestingly, analysis of the DfT indicators in the light of this information suggested that most of them had little relevance to the travel habits (and therefore social exclusion/inclusion) of many older people (Table 5). Clearly, the first three indicators do not apply to older people (unless they are working; they are not able to claim Jobseekers' Allowance ${ }^{3}$ when they are no longer of official working age, i.e. over 65 for men and 60 for women). Hospital and GP access is relevant to this group, although analysis of the statistics suggests that only a small minority

\footnotetext{
${ }^{3}$ Jobseekers' Allowance is a welfare payment made to those on low income not currently in employment but actively seeking work.
} 
Table 4: Trips per person per year by purpose and travel difficulties.

\begin{tabular}{lccc}
\hline \multirow{2}{*}{ Journey purpose } & \multicolumn{2}{c}{ Aged 60+ } & \multirow{2}{*}{ All ages mean } \\
\cline { 2 - 3 } & Travel difficulties & No difficulties & \\
\hline Work \& Education & 14 & 83 & 275 \\
Shopping \& Personal & 290 & 452 & 309 \\
Business & & & \\
Leisure \& Social & 191 & 366 & 313 \\
Escort & 33 & 61 & 129 \\
Other & 1 & 2 & 2 \\
\hline Total & 529 & 964 & 1029 \\
\hline
\end{tabular}

Source: Department of the Environment, Transport and the Regions (2003a,b).

make regular trips to a hospital (Department of the Environment, Transport and the Regions 2001), and it is not clear whether the travel times are appropriate as the thresholds used in the DfT hospitals indicator are based on median journey times for all medical trips and not journey times to hospitals per se. The indicator for access to a major center has since been replaced with access to a supermarket; this may or may not be relevant, depending on whether people want to go to a supermarket to shop for food and other items.

\subsection{Establishing benchmarks that reflect the priorities of the elderly}

Table 6 sets out the preliminary benchmarks arising from the pilot focus group in Rotherham. The focus group made it quite clear that the most important consideration was ease of leaving the house and of simply "getting around." Rather than being concerned about any particular destination, people wanted to be able to get out-their concern was with mobility rather than with access. They were more concerned about the number of times they were able to do particular things, rather than with the attributes of the journeys for those purposes. The time element, considered so crucial by the DfT, turned out to be relatively unimportant to many in this group, who are not burdened with having to accomplish the variety of journeys and tasks common to many younger and working people.

The London and Hertfordshire focus groups generally agreed with the concerns of the Rotherham group and with the approach adopted. They put forward the figures presented as a basic minimum with the idea that these trips should be able to be undertaken without great stress, danger, expense, etc. —or in other words with "reasonable ease." Two additional activities were suggested for inclusion in the benchmarks: trips to the post office and medical trips (Table 7). Medical trips included trips to visit friends and relatives in hospital, etc.

\subsection{Results from AMELIA}

\section{Walking journeys}

Some analysis has been carried out using the data collected in St. Albans as part of the design process, in order to help establish ways of representing the data and to ensure that AMELIA is sensitive to the type of issue that it will be used to analyze. 
Table 5: A summary of the relevance of the UK national accessibility indicators to older people.

\begin{tabular}{ll}
\hline Indicator & Relevance to Older people \\
\hline a) & Percentage of pupils of compulsory school age \\
within 15 and 30 minutes of a primary school & \\
and 20 and 40 minutes of a secondary school \\
by public transport
\end{tabular}

a) Percentage of people of working age (16-74) within 20 and 40 minutes of work by public transport

b) Percentage of people in receipt of Jobseekers' Allowance within 20 and 40 minutes of work by public transport

Relevant to a limited number of people within this group, or for relatively few trips per year and inappropriate travel times specified

a) Percentage of households within 30 and 60 minutes of a hospital by public transport

b) Percentage of households without access to a car within 30 and 60 minutes of a hospital by public transport

Relevant to a limited number of people within this group, or for relatively few trips per year

a) Percentage of households within 15 and 30 minutes of a GP by public transport

b) Percentage of households without access to a car within 15 and 30 minutes of a GP by public Relevant trip purpose but inappropriate travel times specified transport

a) Percentage of households within 15 and 30 minutes of a major center by public transport

b) Percentage of households without access to a Relevant car within 15 and 30 minutes of a major center by public transport 
Table 6: Preliminary benchmarking ideas for older people (Rotherham minima).

\begin{tabular}{|c|c|}
\hline Activity & No. journeys required \\
\hline Food shopping & twice a week \\
\hline Comparison shopping & twice a month \\
\hline Social or recreational activity & twice a week \\
\hline Holiday & twice a year \\
\hline $\begin{array}{l}\text { Structured day time activity appropriate to } \\
\text { need }^{*}\end{array}$ & 2-10 times a week \\
\hline \multicolumn{2}{|c|}{$\begin{array}{l}{ }^{*} \text { This might be, for example, a visit to a day center or attendance at religious } \\
\text { services and is dependent on individual needs. }\end{array}$} \\
\hline \multicolumn{2}{|c|}{ Table 7: Additional benchmarks proposed by the London and Hertfordshire focus grou } \\
\hline Activity & No. journeys required \\
\hline Post Office & twice a week \\
\hline Medical trip or visit & twice a month \\
\hline
\end{tabular}

One issue that had to be considered was the extent to which accessibility varies depending on the extent to which various obstructions are taken into account. For this purpose three types of obstruction were considered:

- Crossings without dropped kerbs;

- Footways with an effective width of less than one meter;

- Dropped kerbs with gradients of more than five degrees.

People in wheelchairs may not be able to cross a road without a dropped kerb. Furthermore, people who need dropped kerbs to make a journey need them at every crossing that they use to reach their destination. Also, they need them not to be too steep. The figure of five degrees used here was based on guidance in the Inclusive Mobility Guidelines (Department for Transport 2005). The width of the footway is also an issue, as indicated in Table 8. For illustrative purposes, a minimum width of one meter was considered here. To show the possible impact of these obstructions to the 1,436 people aged 60 or over living in the city center, the effects of the obstructions to three key places in St. Albans are shown in Table 8. The key places are: the Old Town Hall, which houses the tourist information point and is adjacent to the street market; the main railway station, from which trains go to London; and the city hospital.

Nineteen percent of the people aged 60 and above cannot reach any of the key places if they need to use dropped kerbs at road crossings. This was the obstruction that affected the least people. The effective width of the footway was found to be the obstacle that affected the second-largest number of people, with 30 percent of elderly people unable to reach the three 
key points if they are unable to pass through a gap of less than one meter. The obstacle that was found to cause the largest obstruction was dropped kerbs with a gradient of over five degrees. Fifty-six percent of the population would not be able to reach the Old Town Hall if they could not manage dropped kerbs that are steeper than five degrees, 94 percent would not be able to reach the hospital, and none would be able reach the station. If people cannot manage to overcome any of the obstructions, most would not be able to reach the Old Town Hall (87\%) or the hospital (94\%), and none of them could reach the station.

This analysis showed that, despite the high levels of accessibility in the city center, there are some obstructions. In particular, although many street crossings include dropped kerbs, some of these have steep gradients that present problems. Width restrictions on the footway also stop some people from reaching key points in St Albans.

Table 8: Number of the 1,436 people aged 60 or over living in the center of St Albans unable to overcome barriers to walking in order to reach key buildings in the city center.

\begin{tabular}{|c|c|c|c|c|c|c|}
\hline \multirow{2}{*}{ Obstruction } & \multicolumn{2}{|c|}{ Old Town Hall } & \multicolumn{2}{|c|}{ Railway station } & \multicolumn{2}{|c|}{ City Hospital } \\
\hline & No. & $\%$ & No. & $\%$ & No. & $\%$ \\
\hline Crossings without dropped kerbs & 273 & 19 & 272 & 19 & 273 & 19 \\
\hline Footways with effective width $<1 \mathrm{~m}$ & 424 & 30 & 424 & 30 & 424 & 30 \\
\hline Dropped kerb gradient $>5$ degrees & 797 & 56 & 1436 & 100 & 1353 & 94 \\
\hline All of the above & 1252 & 87 & 1436 & 100 & 1353 & 94 \\
\hline
\end{tabular}

A second major access issue is being able to enter buildings. Data were collected on the access to 588 buildings in the center of St Albans, and building access categories were ranked in order of difficulty of overcoming them. The simplest was level access, then a lift that creates level access (assuming that it is working), a slope, a ramp, and finally steps; this last category was further broken down into a single step, two steps, or three or more. This ranking is subjective, but is probably valid for wheelchair users or those with serious walking difficulties. A person in a self-propelled wheelchair should be able to negotiate level access, lifts, and slopes. They may be able to go up a ramp, depending on the gradient. Steps are likely to pose a serious problem. A person pushing a wheelchair will probably be able to push it up a ramp and negotiate one step, depending on the height. Some may be able to negotiate two steps, but three or more are likely to be an insurmountable barrier.

Table 9 shows cumulative percentages of the numbers of buildings that could be accessed by those able to use the various means. About 40 percent of the buildings have level access. It can be seen that the most accessible type of building was clothing and accessories shops, with 64 percent offering level access. The three other retail categories were the next three most accessible types of building, with food, drink, and multi-item shops the least accessible type of shop in terms of level access. Only five buildings had only lift access (a number have lift access to upper floors, but this study focused on access up to and including the entrance, not beyond). Some of these were on the upper floor of a modern shopping center. None of the sports and entertainment facilities had level access, but some had lifts. About six percent of the buildings had a slope for access, and another four percent a ramp. The type of amenity with fewest buildings offering a ramp or better access was eating and drinking facilities-restaurants, cafés, bars and public houses. When one step was included in the access categories, retail was still the most accessible 
category, followed by other commercial services, followed by education and health. The least accessible building type was attractions, of which there were only six, followed by sport and entertainment, and legal and financial services. The last category was the largest. Many of these were in offices above shops, often up rather narrow staircases. Overall, it can be seen that there was considerable variety in the access to the buildings in the center of St Albans.

\section{Public transport journeys}

It was made clear by the focus groups that overall journey time was not critically important to older people. Cost was also not a major consideration, as the majority of older persons had a bus pass that gave them access to concessionary fares. Of greater importance, at least to those in Hertfordshire, was having to change buses during the trip; this was considered less of a problem in the London Borough of Camden where buses operate at a much higher frequency. The Hertfordshire focus groups expressed a strong dislike for journeys that involved one or more bus changes. Thus, the model was limited to direct bus services only, with no constraints placed on journey time or cost.

While some people may be able to reach the city center by foot (or live there), many others will need to arrive by mechanized modes-either bus or car. As Table 8 shows, many people with mobility difficulties can only walk limited distances without a rest. Table 10 shows the percentages of the various types of building that were found to be within various distances of the bus stops in the center of St Albans. For example, 20 percent of eating and drinking facilities were within 50 meters of a bus stop, and 46 percent were within 100 meters of one. To some extent, this is a measure of dispersal, with food, drink, and multi-item shops being the category most highly represented within 50 meters of a bus stop, and also having the greatest representation within the 100-meter and 150-meter bands. The types of building that tended to be least-well-served by bus stops were clothing and accessories shops, sports and entertainment facilities, and eating and drinking establishments. Not surprisingly, the facilities that were least-well-served by bus stops, as shown by the percentage beyond 200 meters from any bus stop, were the smallest categories: motoring shops and attractions. The buildings best served by bus stops within 200 meters were legal and financial services and food, drink, and multi-item shops.

It was possible to examine levels of access to various facilities taking into account the three obstacles shown in Table 8 (crossings without dropped kerbs, footways with an effective width of less than one meter, and dropped kerbs with a gradient of more than five degrees). Table 11 shows the number of buildings that were found to be within various distance bands of the bus stops avoiding all three types of obstacle. The presence of obstacles reduced the number of buildings within 50 meters of bus stops from 26 percent to 21 percent. The facilities that had the largest decrease, in terms of being within 50 metros of a bus stop, were eating and drinking facilities and sports and entertainment facilities. When the obstacles were considered, there were reductions in the number of buildings within all the distance bands; for the 200-meter band, the reduction was from 77 percent to 64 percent.

Table 12 shows the results obtained when the model was used to assess the level of access by public transport to one of the key facilities (the Old Town Hall) at different times of day and using different maximum walking distances for both ingress and egress elements of the journey, both with and without obstructions. In this instance, access was modeled for the elderly population of an extended area - the district of St Albans. (The total population aged 60+ for St Albans District is 25,178). 
Table 9: Cumulative percentages of various types of building that can be accessed by those able to overcome various barriers to entry.

\begin{tabular}{|c|c|c|c|c|c|c|c|c|}
\hline \multirow{3}{*}{ Building Class } & \multicolumn{7}{|c|}{ Access type } & \multirow{3}{*}{$\begin{array}{c}\text { Total } \\
\text { number of } \\
\text { bldgs. }\end{array}$} \\
\hline & \multirow[t]{2}{*}{ Level } & \multirow[t]{2}{*}{ Lifts } & \multirow[t]{2}{*}{ Slope } & \multirow[t]{2}{*}{ Ramp } & \multicolumn{3}{|c|}{ Steps } & \\
\hline & & & & & 1 & 2 & $3+$ & \\
\hline Eating and drinking & 32 & 32 & 37 & 37 & 81 & 88 & 100 & 113 \\
\hline \multicolumn{9}{|l|}{ Commercial services: } \\
\hline Legal and financial & 32 & 32 & 41 & 46 & 68 & 76 & 100 & 37 \\
\hline Other commercial services & 34 & 34 & 38 & 38 & 88 & 95 & 100 & 97 \\
\hline Attractions & 33 & 33 & 33 & 50 & 67 & 67 & 100 & 6 \\
\hline Sport and entertainment & 0 & 13 & 38 & 56 & 75 & 75 & 100 & 16 \\
\hline Education and health & 35 & 35 & 42 & 50 & 85 & 88 & 100 & 48 \\
\hline Public Infrastructure & 30 & 37 & 50 & 57 & 77 & 87 & 100 & 30 \\
\hline \multicolumn{9}{|l|}{ Retail: } \\
\hline Clothing and accessories & 64 & 65 & 65 & 65 & 93 & 99 & 100 & 84 \\
\hline Food, drink and multi-item & 37 & 37 & 50 & 53 & 93 & 100 & 100 & 30 \\
\hline Household, office, leisure and garden & 47 & 47 & 54 & 55 & 95 & 99 & 100 & 123 \\
\hline Motoring & 50 & 50 & 100 & 100 & 100 & 100 & 100 & 4 \\
\hline Overall percentage & 40 & 41 & 47 & 50 & 86 & 92 & 100 & \\
\hline Total number of buildings & 234 & 5 & 38 & 15 & 216 & 35 & 45 & 588 \\
\hline
\end{tabular}

Seventeen percent of the people living in St Albans would be unable to reach the town hall by direct public bus, if they were unable to walk further than 200 meters. This number increases significantly (to 40\%) if the travelers are unable to overcome any of the obstacles (lack of dropped kerbs, steep dropped kerbs, and narrow footways). In the evening, lack of public transport services increases these figures to 59 percent and 83 percent respectively. The numbers of elderly persons unable to reach this key destination increased as the maximum distance it was assumed they were able to walk decreased. For example, at $100 \mathrm{~m}, 67$ percent would be unable to reach the town hall during the day, even if they could overcome obstacles on footway (Table 12). If the older people living in St Albans were unable to walk further than $50 \mathrm{~m}$, then no one would be able to reach the Old Town Hall, regardless of their ability to overcome obstacles on the footway or of the time of day. 
Table 10: Percentage of various types of buildings in St Albans' city center accessible within distance bands from bus stops.

\begin{tabular}{lccccc}
\hline \multirow{2}{*}{ Building Class } & \multicolumn{4}{c}{ Distance $(\mathrm{m})$} & \multirow{2}{*}{$\begin{array}{c}\text { Total no. of } \\
\text { buildings }\end{array}$} \\
\cline { 2 - 5 } & 50 & 100 & 150 & 200 & \\
\hline Eating and drinking & 20 & 46 & 67 & 75 & 113 \\
Commercial services: & & & & & \\
Legal and financial & 51 & 68 & 86 & 95 & 37 \\
Other commercial services & 27 & 65 & 84 & 87 & 97 \\
Attractions & 33 & 50 & 50 & 50 & 6 \\
Sport and entertainment & 19 & 50 & 69 & 69 & 16 \\
Education and health & 27 & 58 & 63 & 69 & 48 \\
Public Infrastructure & 20 & 40 & 50 & 57 & 30 \\
Retail: & & & & & 84 \\
Clothing and accessories & 18 & 51 & 69 & 75 & 30 \\
Food, drink and multi-item & 47 & 80 & 90 & 90 & 123 \\
Household, office, leisure and garden & 26 & 54 & 70 & 74 & 4 \\
Motoring & 25 & 25 & 25 & 25 & 588 \\
\hline Total & 26 & 55 & 71 & 77 & \\
\hline
\end{tabular}

Table 11: Percentage of various types of buildings in St Albans' city center accessible within distance bands from bus stops, taking into account obstructions.

\begin{tabular}{lcccccc}
\hline \multirow{2}{*}{ Building Class } & \multicolumn{4}{c}{ Distance $(\mathrm{m})$} & \multirow{2}{*}{$\begin{array}{c}\text { Total no. of } \\
\text { buildings }\end{array}$} \\
\cline { 2 - 5 } & 50 & 100 & 150 & 200 & 113 \\
\hline Eating and drinking & 13 & 31 & 52 & 58 & \\
Commercial services: & & & & & 37 \\
Legal and financial & 41 & 51 & 68 & 68 & 97 \\
Other commercial services & 24 & 53 & 71 & 76 & 6 \\
Attractions & 33 & 33 & 33 & 50 & 16 \\
Sport and entertainment & 13 & 25 & 38 & 44 & 48 \\
Education and health & 23 & 44 & 52 & 56 & 30 \\
Public Infrastructure & 17 & 27 & 37 & 40 & \\
Retail: & & & & & 84 \\
Clothing and accessories & 17 & 44 & 64 & 71 & 30 \\
Food, drink and multi-item & 37 & 57 & 70 & 70 & 4 \\
Household, office, leisure and garden & 19 & 41 & 59 & 64 & 588 \\
Motoring & 25 & 25 & 25 & 25 & \\
\hline Total & 21 & 42 & 59 & 64 & 5 \\
\hline
\end{tabular}


Table 12: Percentage of St Albans District population (age 60 and over) who can reach the Town Hall using a direct public bus, at different times of day and allowing for different maximum walking distances and effects of obstructions of the footway.

\begin{tabular}{lccccc}
\hline \multirow{2}{*}{$\begin{array}{l}\text { Max walking } \\
\text { distance }(\mathrm{m})\end{array}$} & \multicolumn{2}{c}{ Morning off-peak } & & \multicolumn{2}{c}{ Evening } \\
\cline { 2 - 3 } \cline { 5 - 6 } & $\begin{array}{c}\text { Without } \\
\text { Obstructions }\end{array}$ & $\begin{array}{c}\text { With } \\
\text { Obstructions }\end{array}$ & & $\begin{array}{c}\text { Without } \\
\text { Obstructions }\end{array}$ & $\begin{array}{c}\text { With } \\
\text { Obstructions }\end{array}$ \\
\hline 200 & 83 & 60 & & 41 & 17 \\
150 & 74 & 57 & & 24 & 14 \\
100 & 33 & 33 & & 2 & 2 \\
50 & 0 & 0 & & 0 & 0 \\
\hline
\end{tabular}

\section{Conclusions}

The travel patterns of elderly people in Great Britain differ markedly from the national average. Typically, elderly persons make very few trips for work or educational purposes, while making make far more food shopping trips than average and twice the number of medical trips. (However, medical trips still account for a very small percentage of total trips.) Generally, elderly people value just being able to get "out and about."

It is clear that the DfT indicators are not suitable for evaluating the travel needs of elderly people, as these indicators do not reflect the types of journeys elderly people do make and aspire to make. Additionally, the format of the national accessibility indicators, which are based on journey time thresholds, do not reflect older people's attitudes to travel. The results from focus groups suggest that overall journey time is generally not an issue for the elderly. Furthermore, it is clear that the mobility of older people is strongly influenced by myriad micro-level circumstances. In order to compare potential policy options, these micro-level details must be documented and incorporated into benchmarks.

This research established and refined a set of benchmarks. These were based on a minimum number of times an elderly person should be able to accomplish a particularly activity or complete a type of trip over a given period, (i.e., a week) without undue stress, danger or expense. The activities covered included shopping (food and comparison), social, recreational and structured activities, holidays, trips to the post office, and medical visits. The minima were generally slightly less than the average number of journeys (round trips) recorded in the NTS, with the benchmarks set between nine and 17 activities per week. An elderly person who experiences no travel difficulties will, on average, make 36 trips (i.e. 18 journeys per week assuming two trips per journey).

Work has begun to establish the micro-level criteria that will allow these minima to be modeled. It has been possible to base some of these criteria, particularly those related to the physical attributes of the footway and the wider built environment, on Government guidance. Others, such as those relating to attitudes to travel on public transport, are being developed through focus groups.

Using these micro-level criteria, some initial analysis has been done to establish the accessibility of various destinations. The analysis showed that many of the micro-level details that influence the mobility of older people can be documented and incorporated into accessibility 
benchmarks, and that these do make a substantial difference to the assessment of whether or not an activity or destination can be reached.

Further work is needed to refine and expand the micro-level criteria and to validate the benchmarks so that they can be incorporated into the AMELIA tool.

This research highlighted the importance of involving those at whom social exclusion and accessibility policies are addressed in developing suitable benchmarks and indicators. The approach adopted can be adapted for any population, and not just within the UK. The benchmarks that were derived can be difficult to model using conventional accessibility measures but many of the barriers and constraints to movement can be captured and incorporated within a GIS. The difference that this type of approach makes to assessments of accessibility is significant.

\section{Acknowledgments}

This paper was written as part of a project titled "Accessibility and User Needs in Transport" funded by the UK Engineering and Physical Sciences Research Council (EPSRC) under grant GR/S90867/01 as part of its Sustainable Urban Environments Programme. The National Travel Survey data was provided to the Department of the Environment, Transport and the Regions (DETR) via the UK Data Archive and is Crown Copyright. DETR and the UK Data Archive bear no responsibility for the analysis and interpretation of the NTS data contained in this paper. The cooperation of Hertfordshire County Council, the London Borough of Camden, and Rotherham Community Transport is greatly appreciated.

\section{References}

Beale, L., K. Field, D. Briggs, P. Picton, and H. Matthews. 2003. Mapping for wheelchair users: Route navigation in urban spaces. The Cartographic Journal, 43(1):68-81.

Burchardt, T., J. L. Grand, and D. Piachaud. 2002. Degrees of exclusion: Developing a dynamic, multi-dimensional measure. In T. Burchardt, J. L. Grand, and D. Piachaud, eds., Understanding Social Exclusion. Oxford: Oxford University Press.

Cabinet Office. 2007. URL http://www.cabinetoffice.gov.uk.

Department for Transport. 2005. Inclusive mobility. Originally published 2002, updated 2005, URL http://www.dft.gov.uk/stellent/groups/dft_mobility/documents/page/ dft_mobility_503282.hcsp.

Department of the Environment, Transport and the Regions. 2001. Older people: Their transport needs and requirements. Technical report, Mobility and Inclusion Unit, London.

Department of the Environment, Transport and the Regions. 2003a. National travel survey, 1998-2000. Computer file, distributed by UK Data Archive. SN:4584.

Department of the Environment, Transport and the Regions. 2003b. National travel survey, 1999-2001. Computer file, distributed by UK Data Archive.

Department of the Environment, Transport and the Regions/TRaC. 2000. Social exclusion and the provision and availability of public transport. Technical report, Mobility and Inclusion Unit.

EC. 2004. Town and infrastructure planning for safety and urban quality: State-of-the-art report. Technical Report COST Action C6, European Commission, Brussels. 
ECMT. 2006. Improving transport accessibility for all: A guide to good practice. URL http: //www.internationaltransportforum.org/europe/ecmt/pubpdf/06TPHguide.pdf.

Geurs, K. and J. R. V. Eck. 2001. Accessibility measures: Review and applications. RIVM report 408505 006, National Institute of Public Health and Environment, Bilthoven.

Geurs, K. and B. Wee. 2004. Accessibility evaluation of land-use and transport strategies: Review and research directions. Journal of Transport Geography, (12):127-140.

Halden, D., P. Jones, and S. Wixey. 2005. Accessibility analysis literature review. SAMP working paper 3, Transport Studies Group, University of Westminster. URL http://home.wmin. ac.uk/transport/download/SAMP_WP3_Accessibility_Modelling.pdf.

Handy, S. and D. Niemeier. 1997. Measuring accessibility: An exploration of issues and alternatives. Environment and Planning A, 29(7):1175-1194.

Hayllar, O., P. McDonnell, C. Mottau, and D. Salathiel. 2005. National travel survey 2003 and 2004. Technical report, UK Department for Transport, London.

Jones, P., H. Titheridge, S. Wixey, and G. Christodoulou. 2006. 'walc': Measuring pedestrian access to local bus and rail stations, taking into account traveller perceptions. Paper presented at the 11th International Conference on Travel Behaviour Research, Kyoto.

Jones, P. and S. Wixey. 2005. Measuring accessibility as experienced by different socially disadvantaged groups. Samp end of project summary report, University of Westminster. URL http://home.wmin.ac.uk/transport/download/SAMP_WP8_Final_Summary_ Report.pdf.

Mackett, R., K. Achuthan, and H. Titheridge. 2007. Conflicts between macro level policy and micro level implementation-the case of social exclusion. Eleventh World Conference on Transport Research, Berkeley, California.

Male, S. and J. Spiteri. 2005. Reasonable access to the physical built environment for the disabled-a methodological exploration. In Proceedings of the Queensland University of Technology Research Week International Conference. Brisbane.

Matisse Consortium. 2003a. Manual for assessing the impacts of transport policy on social exclusion. Report prepared for the European Commission Directorate General for Employment and Social Affairs. Available from .

Matisse Consortium. 2003b. Transport strategies to combat social exclusion. Final report to the European Commission Directorate General for Employment and Social Affairs. Available from .

Matthews, H., L. Beale, P. Picton, and D. Briggs. 2003. Modelling access with GIS in urban systems (MAGUS): Capturing the experience of wheelchair users. Area, 35(1):34-45.

Miller, H. 2005. Place-based versus people-based accessibility. In D. Levinson and K. Krizek, eds., Access to Destinations. Oxford: Elsevier.

National Statistics. 2004. Census 2001: National report and standard tables for wards in England and Wales. Technical report, National Statistics, London.

Oppenheim, C. 1998. An inclusive society: Strategies for tackling poverty. London: Institute for Public Policy Research.

Rawls, J. 1971. A theory of justice. Oxford: Oxford University Press, 1999 edition.

Reneland, M. 2005. Accessibility calculations in six Swedish towns. In A. Kungolos, C. Brebbia, and E. Beriatos, eds., Sustainable Development and Planning II, volume 2, pp. 903-912. Southampton: WIT Press. 
Solomon, J. and H. Titheridge. 2006. Accessibility indicators and the policy goal of the reduction of transport-related social exclusion. CTS working paper 2006/3, Centre for Transport Studies, University College London, London.

Solomon, J. and H. Titheridge. 2007. Transport equity and the elderly. Paper presented at the 9th NECTAR conference, Porto, Portugal.

United States Access Board. 2004. The Americans with Disabilities Act and Architectural Barriers Act accessibility guidelines. URL http://www.access-board.gov/ADA-ABA/final. htm.

World Bank. 2006. World Development Report 2006: Equity and development. URL http: //econ.worldbank.org. 